\title{
Fragilidade a inundações da Bacia Hidrográfica do Rio Baquirivu-Guaçu (Guarulhos, SP)
}

\author{
Márcio Nunes MANZANO', Anderson Targino da Silva FERREIRA' ${ }^{7}$, Antonio Roberto \\ SAAD², Edilson PIZZATO², William de QUEIROZ \& Fabricio Bau DALMAS ${ }^{1}$ \\ 1 Programa de Mestrado em Análise Geoambiental, Universidade Univeritas UNG. Praça Tereza Cristina, \\ 228, CEP 07023-070, Guarulhos, SP, Brasil (marcionmanzano@ig.com.br, fdalmas@prof.ung.br, \\ atargino@prof.ung.br,wqguarulhos@gmail.com,saadhome@uol.com.br). \\ 2 Programa de Pós-graduação em Geociências, Instituto de Geociências, Universidade de São Paulo. Rua \\ do Lago, 562, CEP 05508-080, São Paulo, SP, Brasil (pissato@usp.br). \\ 3 Secretaria de Educação do Estado de São Paulo. Praça da República, 53, CEP 01045-903, São Paulo, SP, \\ Brasil (wqguarulhos@gmail.com).
}

\begin{abstract}
Resumo. O Município de Guarulhos, segunda maior cidade do Estado de São Paulo, encontrase em franca expansão urbana e não foge à regra de ter problemas de planejamento e de degradação ambiental, características do desenvolvimento de algumas sociedades modernas. Em consequência deste desequilíbrio, verificam-se impactos ambientais negativos significativos na Bacia Hidrográfica do Rio Baquirivu-Guaçu, localizada em Guarulhos e onde está situado o Aeroporto Internacional de Guarulhos. Assim, o objetivo desta pesquisa foi de mapear as áreas com fragilidade a inundações da Bacia Hidrográfıca do Rio Baquirivu-Guaçu. Foram aplicadas técnicas de geoprocessamento na metodologia: análise multicritério com base vetorial na escala 1:50.000; e técnicas de sensoriamento remoto, Classificador de Máxima Verossimilhança, com imagem do sensor OLI (Landsat 8). Observou-se que as áreas de maior fragilidade a inundações estão situadas na planície fluvial do Rio Baquirivu-Guaçu, onde está localizado o Aeroporto Internacional de Guarulhos. Através dos mapas elaborados e registro de trabalho de campo, ficou claro que a falta de infraestrutura urbana (coleta de lixo e ocupação de áreas inadequadas para contrução de residências) favorecem a transformação dos cursos d'água em verdadeiros depósitos de lixo e sedimentos, comprometendo o adequado funcionamento dos sistemas de drenagem, pela falta de saneamento básico no entorno da Bacia do Rio Baquirivu Guaçu. Palavras-chave. aeroporto, impactos ambientais, fragilidade ambiental, inundações
\end{abstract}

\begin{abstract}
FLOODING FRAGILITY OF THE BAQUIRIVU-GUAÇU RIVER WATERSHED (GUARULHOS, SP). The municipality of Guarulhos, the second largest city in the State of São Paulo, is in frank urban expansion and does not escape the rule of having problems of planning and environmental degradation, characteristics of the development of some modern societies. As a result of this imbalance, there are significant negative environmental impacts in the Baquirivu-Guaçu River Watershed, located in Guarulhos and where Guarulhos International Airport is located. The objective of this research was to map areas with fragility to floods in the Baquirivu-Guaçu Watershed. Geoprocessing techniques were applied in the methodology: multicriteria analysis with vectorial basis in scale 1:50,000; and remote sensing techniques, Maximum Likelihood Classifier, with OLI sensor image (Landsat 8). It was observed that the areas of greatest fragility to the floods are located in the Baquriri-Guaçu river plain, where the Guarulhos International Airport is located and through the elaborated maps and field records it was possible to see that the lack of urban infrastructure it was possible to see that the lack of urban infrastructure (inadequate urban waste disposal and occupation of inadequate areas for housing construction) favored the transformation of watercourses into true garbage and sediment deposits, jeopardizing the proper functioning of the drainage systems due to lack of basic sanitation around the Baquirivu Guaçu River Watershed.
\end{abstract}

Keywords. airports, environmental impacts, environmental fragility, floods. 


\section{Introdução}

O desenvolvimento da sociedade moderna, principalmente a urbana, tem ocorrido de forma desordenada, isenta de qualquer planejamento, à custa de níveis, cada vez maiores, de poluição e de degradação ambiental. Como resultados desse cenário em desequilíbrio, verificam-se impactos significativos, que comprometem a qualidade ambiental, notadamente das grandes metrópoles (Braga et al., 2005).

Para a maioria dos países, os grandes centros urbanos, principalmente as capitais, servem como excelente local para efetuarem-se negócios e alavancar a economia nacional. No Brasil, este aspecto se torna muito evidente, pois o seu grau de urbanização abriga cerca de $80 \%$ do total da população. Nas regiões metropolitanas via de regra, esse aumento populacional é acompanhado pelo crescimento da pobreza (Mesquita, 2011).

Segundo Ramalho et al. (1999), pela forma acelerada com que se verifica a urbanização, o Poder Público não consegue prover a população dos grandes aglomerados urbanos de moradia adequada, água potável, saneamento básico, coleta de lixo, escolas, hospitais, centros de saúde e transportes. Assim, torna-se cada vez mais evidente a presença de um cenário urbano em expansão, diretamente ameaçado por riscos e problemas ambientais, principalmente em suas periferias. De acordo com lelo (2015), o processo de urbanização acelerado e desordenado pode acarretar processos de desequilíbrio ambiental, como o desequilíbrio no sistema hidrológico e neste contexto, as enchentes e inundações nas áreas urbanas tornaram-se grandes problemas, em virtude dos impactos do uso do solo indevido.

Toda modificação no estado natural do meio, tal como desmatamento, falta de planejamento no uso e ocupação do solo, disposição inadequada de resíduos sólidos e inadequado sistema de saneamento pode resultar numa série de efeitos adversos, ao que se chama de fragilidade.

Com o intuito de se ampliar a base de informações para poder-se conhecer as fragilidades de determinado local, deve-se buscar técnicas e instrumentos que reduzam custos e tempo. As técnicas de Sensoriamento Remoto e os Sistemas de Informação Geográfica (SIG), que compõem o Geoprocessamento, são importantes ferramentas no monitoramento ambiental, pois permite analisar a dinâmica do uso e ocupação do solo, associado às transformações das condições físicas e ambientais do meio (Lorena, 2001).

A escolha do sítio ideal para locação de um aeroporto deve inter-relacionar aspectos sociais, econômicos, políticos e ambientais ou, em outras palavras, a melhor localização do Aeroporto deve ser aquela que agrupe as melhores condições técnicas ao usuário, localização quanto a acesso e que produza os menores impactos ao meio ambiente. Dentro desta ótica, este trabalho teve por objetivo compreender qual a influência da localização do Aeroporto Internacional de Guarulhos na fragilidade a inundações da Bacia Hidrográfica do Rio Baquirivu-Guaçu. Para tanto, elaborou-se um diagnóstico ambiental sobre impacto da influência da localização do Aeroporto Internacional de Guarulhos nas fragilidades natural e ambiental do Sistema Fluvial do Baixo Rio Baquirivu-Guaçu.

\section{2 Área, materiais e métodos}

\section{1 Localização da área}

O Município de Guarulhos, integrante da Região Metropolitana de São Paulo (RMSP), é considerado a segunda maior cidade do Estado de São Paulo, com uma população aproximada de 1,3 milhões de habitantes (IBGE, 2011). Encontra-se em franca expansão urbana e não foge à regra de ter problemas de planejamento e de degradação ambiental. Induzida pelo seu desenvolvimento industrial, viário, aeroportuário, de serviços e por significativas obras civis, que ainda estão por acontecer, o Poder Público do município assiste à urbanização acumular, cada vez mais, problemas geoambientais significativos ocorrendo principalmente nos recursos hídricos em áreas que apresentam condições de fragilidade natural a processos de contaminação e degradação ambiental (Queiroz, 2005; Mesquita, 2011).

A Bacia Hidrográfica do Rio Baquirivu- 
Guaçu (Figura 1), ocupa uma área de 149 km², com a maior parte da sua área inserida no município de Guarulhos e uma pequena parte no território do Município de Arujá, ambos no Estado de São Paulo. Em Guarulhos, sua bacia de drenagem ocupa cerca de 46,6\% do território de Guarulhos, tendo como curso principal o córrego Baquirivu-Guaçu. Este passou por uma série de alterações em seu curso tendo na parte mais baixa do seu trecho canalizado devido à construção e ampliação do aeroporto, bem como a construção de avenidas marginais (Sato \& Andrade, 2017).

\subsection{Camadas ambientais}

O trabalho foi dividido em duas etapas, citam-se: geração dos mapas das camadas ambientais; e geração do mapa da distribuição da fragilidade ambiental. Os mapas das camadas temáticas de: declividade, geomorfologia e solos foram gerados a partir das informações do projeto Bases Geoambientais para um Sistema de Informações Ambientais do Município de
Guarulhos (Processo nº 05/57965-1).

O mapa de uso e ocupação utilizou a classificação de Stewart \& Oke, (2012) e teve como base as imagens orbitais multiespectrais correspondentes às faixas do visível ao infravermelho termal do satélite Landsat-8 (cena 219/076) de 30 de março de 2017 (USGS, 2017). A classificação do tipo de uso e ocupação do solo se deu por meio da classificação supervisionada pelo classificador Máxima Verossimilhança (MAXVER), que se baseia em critérios estatísticos de média, variância e covariância, de modo que o cálculo estima a probabilidade de um pixel pertencer a uma classe pré-definida (amostras de treinamento) (Jensen, 2005; Myint et al., 2011).

A avaliação da exatidão da classificação do mapa de cobertura arbórea foi realizada por meio da técnica analítica do índice kappa ( $k$, Equação 1), que, a partir de áreas de referência (n) distribuídas aleatoriamente na imagem, calcula a medida da diferença e a probabilidade de concordância entre os valores de referência e da classificação (Congalton \& Green, 2009). Como áreas de referência foram utilizados 50

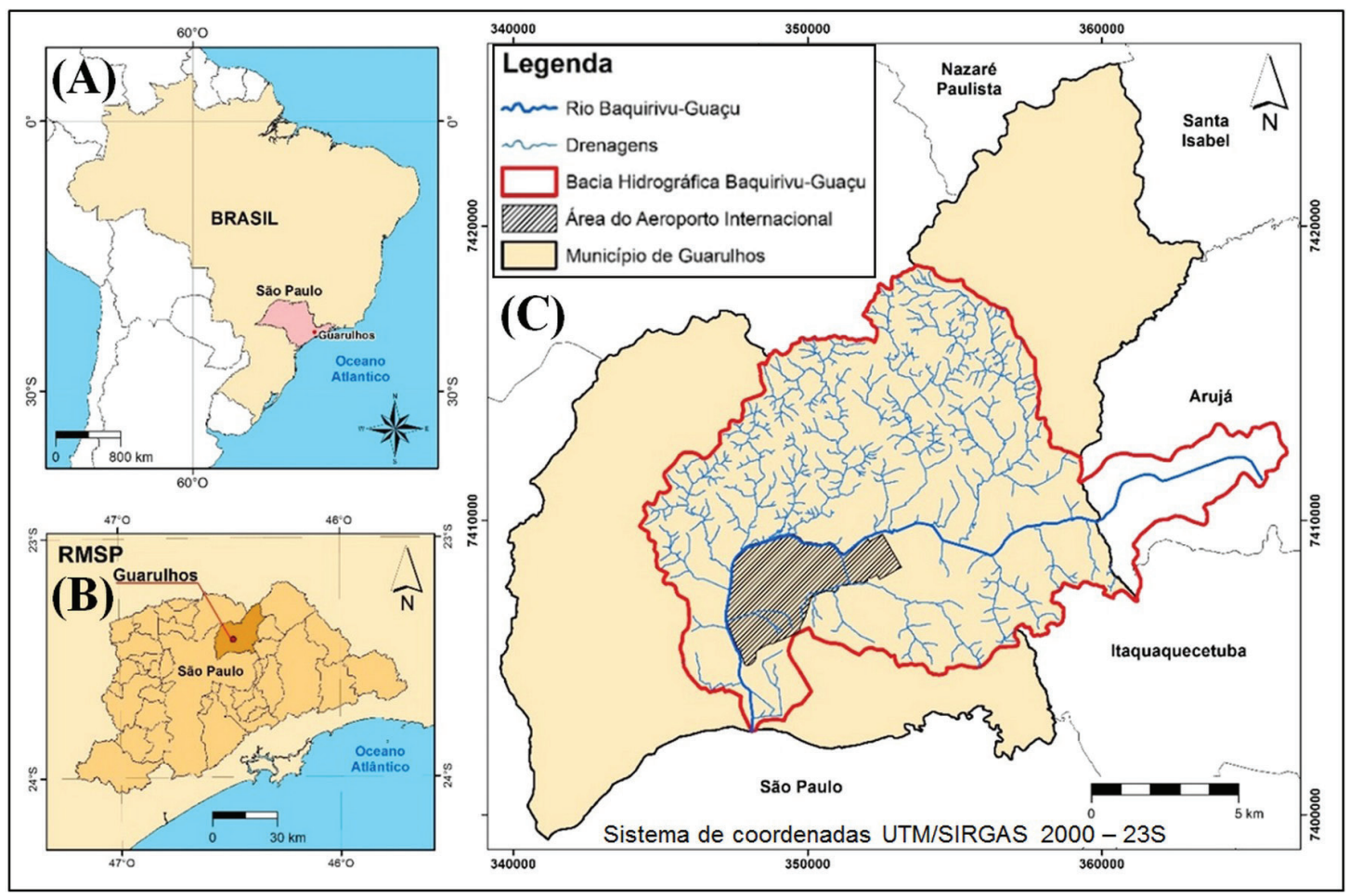

Figura 1. Localização do Estado de São Paulo em relação ao mapa do Brasil (A). Localização do Município de Guarulhos na Região Metropolitana de São Paulo (B). Localização da Bacia do Rio Baquirivu-Guaçu (C).

Figure 1. Location of the State of São Paulo in relation to the map of Brazil (A). Location of the Municipality of Guarulhos in the Metropolitan Region of São Paulo (B). Location of the Baquirivu-Guaçu Watershed (C).

a et al., 2009; CPRM, 2015). 
polígonos (Congalton, 1991), representativos desta classe, observados nas imagens da alta resolução espacial do software Google Earth Pro (Ferreira et al., 2017).

$$
\begin{gathered}
\mathrm{k}=\mathrm{N} \sum X \mathrm{Xii}-\sum X i+X+i / N 2-\sum X i+X+i \\
(\text { Equação 1) }
\end{gathered}
$$

Onde, Xii é a concordância observada; X i+ e $X+i$ (produto das marginais) é a concordância esperada, e N é o total de elementos observados.

\subsection{Fragilidade ambiental}

O mapa da fragilidade ambiental foi gerado a partir da álgebra de acordo com os pesos descritos para cada camada temática (Quadro 1) de acordo com as propostas adaptadas de a proposta de Ross (2012) e lelo (2015). Desse modo, para o parâmetro de declividade, a atribuição de pesos se deu em função do potencial de concentração de fluxo, sendo este mais elevado junto às declividades mais baixas.

Para as unidades geomorfológicas, os morros e colinas obtiveram os menores pesos, sendo que as planícies amplas e restritas, que são comumente inundadas em eventos de altas pluviosidades foram consideradas mais frágeis, portanto com maiores pesos. Em relação às classes de unidades de solos, o processo de atribuição de pesos considerou as seguintes características: o potencial de absorção de água, a profundidade da zona insaturada do perfil, textura (areia, silte ou argila) e profundidade do freático (Guerra, 2003).

Os pesos relativos às classes de uso e ocupação do solo tiveram como base a porcentagem de área impermeável, segundo a classificação de Stewart \& Oke (2012). As classes urbanas compostas por prédios médios e compactos, prédios baixos e compactos e prédios baixos e largos, assim como áreas pavimentadas, podem apresentar de 50\% a 90\% de área impermeabilizada (Quadro 1).

Por fim, todos os mapas foram inseridos em um ambiente de Sistemas de Informação Georreferenciadas (SIG) do software ArcGIS v. 10.2, na escala de 1:50.000 e na mesma base cartográfica, Datum SIRGAS2000, Elipsóide do Sistema Geodésico de Referência de 1980 (Geodetic Reference System 1980 - GRS80) (IBGE, 2005), Sistema de Coordenadas Universal Transversa de Mercator (UTM) e Zona 23 Sul.

Quadro 1. Caracterização dos pesos atribuídos às camadas temáticas.

\begin{tabular}{|c|c|c|c|c|c|}
\hline \multirow{2}{*}{$\begin{array}{l}\text { CAMADA } \\
\text { TEMÁTICA }\end{array}$} & \multicolumn{5}{|c|}{ PESOS } \\
\hline & $\begin{array}{c}\text { MUITO ALTA } \\
5\end{array}$ & $\begin{array}{c}\text { ALTA } \\
4\end{array}$ & $\begin{array}{l}\text { MÉDIA } \\
3\end{array}$ & $\begin{array}{c}\text { BAIXA } \\
2\end{array}$ & $\begin{array}{c}\text { MUITO } \\
\text { BAIXA } \\
1\end{array}$ \\
\hline $\begin{array}{c}\text { Declividade } \\
(\%)\end{array}$ & $<5$ & $5-12$ & $12,1-20$ & $20,1-30$ & $30,1<$ \\
\hline Geomorfologia & Planície restrita & Planície ampla & - & $\begin{array}{l}\text { Colina } \\
\text { pequena }\end{array}$ & $\begin{array}{l}\text { Colina grande; } \\
\text { Morro alto; } \\
\text { Morro baixo; } \\
\text { Morro médio; } \\
\text { Morrote }\end{array}$ \\
\hline Solos & Gleissolo & Argissolo & - & $\begin{array}{c}\text { Cambissolo; } \\
\text { Latossolo }\end{array}$ & - \\
\hline $\begin{array}{l}\text { Uso e ocupação } \\
\text { do solo }\end{array}$ & $\begin{array}{l}\text { Prédios médios } \\
\text { e compactos; } \\
\text { Prédios baixos } \\
\text { e compactos; } \\
\text { Prédios baixos } \\
\text { e largos } \\
\text { áreas pavimentadas }\end{array}$ & $\begin{array}{c}\text { Prédios baixos } \\
\text { e } \\
\text { espaçados; } \\
\text { solo exposto }\end{array}$ & $\begin{array}{c}\text { Vegetação } \\
\text { densa }\end{array}$ & $\begin{array}{l}\text { Vegetação } \\
\text { esparsa }\end{array}$ & Corpo d'água \\
\hline
\end{tabular}

Chart 1. Characterization of the weights assigned to the thematic layers. 


\section{Resultados e discussões}

\subsection{Uso e ocupação do solo}

O Mapa de uso e ocupação do solo (Fig. 2) apresentou 8 classes, sendo que cinco delas são representativas das áreas urbanas (prédios com densidade alta e média, área de asfalto, galpões e solo exposto) e representaram 59\% da área de todo o território da BHB. Essas classes representativas das áreas urbanas receberam os maiores pesos (4 e 5) na etapa de geoprocessamento para elaborar o mapa de vulnerabilidade a inundações devido à baixa infiltração e/ou percolação da água da chuva no solo. Nesses locais são comuns o acúmulo de águas pluviais nas regiões mais baixas da bacia, próximo ao aeroporto internacional de São Paulo e em áreas adjacentes. As demais áreas, representativas das classes vegetadas e de corpos d'água configuraram cerca de $41 \%$ do território da mesma bacia hidrográfica e estão localizadas nas porções mais altas e íngremes da bacia.

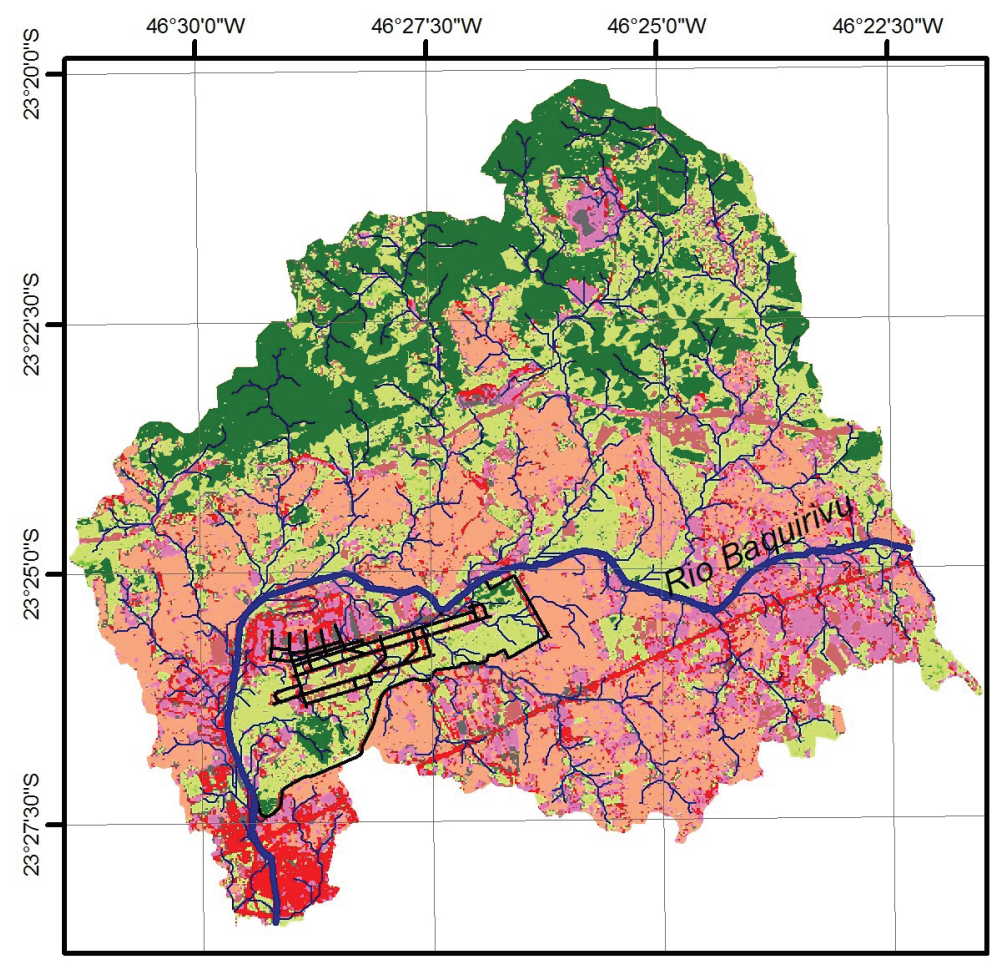

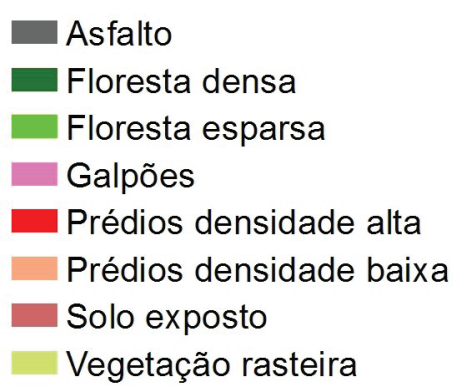

- Pistas aeroporto

$\square$ Limite aeroporto

— Drenagem

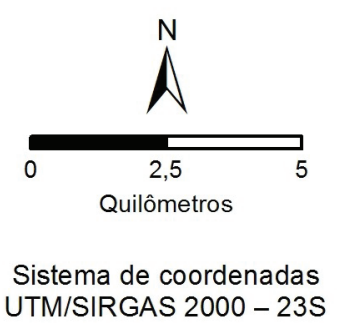

Figura 2. Tipo de cobertura do solo segundo Stewart \& Oke (2012).

Figure 2. Land cover type according to Stewart \& Oke (2012).

Na figura 3 é possível verificar a baixa declividade da área onde Rio Baquirivu-Guaçu desagua no Rio Tietê. A variação de altitude da área de estudo está entre 730 m a 804 m, intervalo representado entre zero e $74 \mathrm{~m}$. As maiores declividades estão na porção norte da área de estudo, onde há predomínio de Floresta densa e esparsa e não há presença de urbanização. Outra área de menor declividade é justamente onde está localizado o Aeroporto Internacional de São Paulo. As elevações medianas estão localizadas nas bordas da planície de inundação do Rio Baquirivu-Guaçu. Segundo Graça et al. (2007), a Bacia Hidrográfica do Rio Baquirivu-Guaçu é balizada, em sua porção norte, pela falha do Rio Jaguari, feição estrutural de direção $N 70^{\circ} \mathrm{E}$.

\subsection{Mapa de vulnerabilidade à inundação}

A aplicação da análise multicritério desenvolvida no ArcGIS resultou num mapa contendo as áreas de fragilidade à inundação na Bacia Hidrográfica do Rio Baquirivu-Guaçu, apresentado em cinco classes de suscetibilidade: muito alta, alta, média, baixa e muito baixa (Fig. 4). A área de estudo apresenta sua vulnerabilidade distribuída de maneira igualitária: 27\% da área estão classificadas entre muito alta e alta 

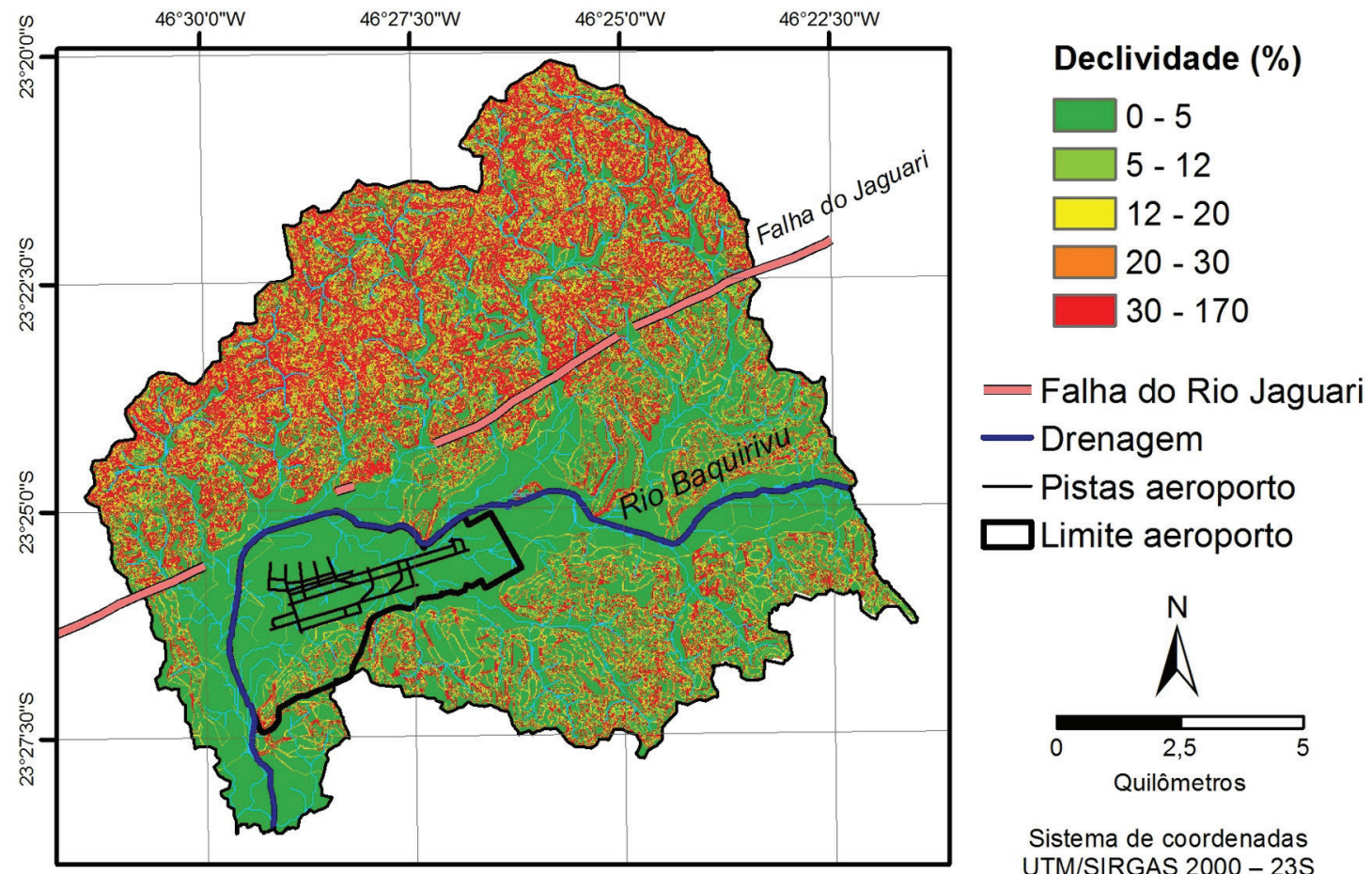

Sistema de coordenadas UTM/SIRGAS $2000-23 S$

Figura 3. Mapa de declividade da Bacia do Rio Baquirivu-Guaçu. Figure 3. Map of slope of the Baquirivu-Guaçu River Watershed.

Quadro 2. Características físicas e geotécnicas distintas entre as margens direita e esquerda do Rio Baquirivu-Guaçu. Chart 2. Physical and geotechnical characteristics between the right and left banks of the Baquirivu-Guaçu river.

\begin{tabular}{|c|c|c|}
\hline Parâmetros & Margem Direita & Margem Esquerda \\
\hline Relevo & $\begin{array}{l}\text { Planícies e terraços fluviais; } \\
\text { colinas e morrotes. } \\
\text { declividades menores que } 15^{\circ} \text {. }\end{array}$ & $\begin{array}{l}\text { Planície aluvial atual, com amplitude } \\
\text { e declividades muito baixas. }\end{array}$ \\
\hline Litologia & $\begin{array}{l}\text { Argilas, areias e cascalhos; } \\
\text { arenitos e conglomerados. }\end{array}$ & Areias, argilas e cascalhos. \\
\hline Solo & Aluviais e argissolos evoluídos & $\begin{array}{l}\text { Hidromórficos, situados em terrenos } \\
\text { mal drenados. }\end{array}$ \\
\hline $\begin{array}{l}\text { Densidade de } \\
\text { drenagem }\end{array}$ & Alta & Média/alta \\
\hline $\begin{array}{l}\text { Padrões dos } \\
\text { canais } \\
\text { fluviais }\end{array}$ & Retilíneos & Sinuosos; localmente retilíneos \\
\hline $\begin{array}{l}\text { Processos } \\
\text { Geotécnicos }\end{array}$ & $\begin{array}{l}\text { Deslizamentos; inundação e } \\
\text { alagamento ao longo dos canais } \\
\text { fluviais tributários. }\end{array}$ & $\begin{array}{l}\text { Processos de inundação, alagamento } \\
\text { e assoreamento. Altura da inundação } \\
\text { de até } 2 \text { metros em relação à borda da } \\
\text { calha do leito regular do curso de água } \\
(\text { Campos, 2011). }\end{array}$ \\
\hline
\end{tabular}


vulnerabilidade; 36\% da área estão em moderada vulnerabilidade; e $37 \%$ em área de baixa a muito baixa vulnerabilidade à inundação.

Da mesma maneira que na geomorfologia e a declividade da área de estudo, a Falha do Rio Jaguari também divide o mapa de vulnerabilidade a inundações em duas grandes áreas: porção norte onde há predomínio de áreas com vulnerabilidade muito baixas a baixas e moderadas; e porção sul, onde se situam as áreas com vulnerabilidades muito altas, altas e também moderadas, coincidente com as avaliações de CPRM (2015). Assim, há grande correção direta do mapa de vulnerabilidade a inundações com os critérios geomorfologia e declividade, pois as áreas de alta e muito alta vulnerabilidade coincidem com a planície ampla do Rio Baquirivu-Guaçu, e a declividade entre zero e $5 \%$. Além disso, estas áreas de alta e muito alta vulnerabilidade a inundações apresentam Gleissolos (solos hidromórficos), que são solos encharcados, frequentemente com presença do freático próximo a superfície.

Em relação à correlação entre as classes de fragilidade à inundação e o mapa de uso do solo, percebe-se que as classes de suscetibilidade a inundação alta e muito alta relacionam-se as áreas nas quais o uso do solo apresenta cobertura vegetal menos representa e maior representatividade de prédios e galpões. Já as áreas com vulnerabilidades baixa e muito baixa à inundações correlacionam-se com vegetações de maior porte e menos urbanização.

\subsubsection{Verificação dos resultados em campo}

Foi realizado um trabalho de campo para validar o mapa de vulnerabilidade a inundação da Bacia Hidrográfica do Rio Baquirivu Guaçu (Figura 5). Para este reconhecimento foram escolhidos quatro pontos situados dentro de áreas classificadas entre alta e muito alta vulnerabilidade à inundação, dentro da área de estudo.

O Ponto 1 (46²4'14.98"O; 2325'52.75"S), localizado próximo ao Shopping Bonsucesso está numa área classificada como Alta Vulnerabilidade à Inundação. Neste ponto, o terreno é bastante plano e com presença de dois córregos. $\mathrm{Na}$ fotografia do ponto 1, pode-se verificar o canal de um dos córregos, que tem à sua direita (após a estrada) uma extensa área plana com vegetação

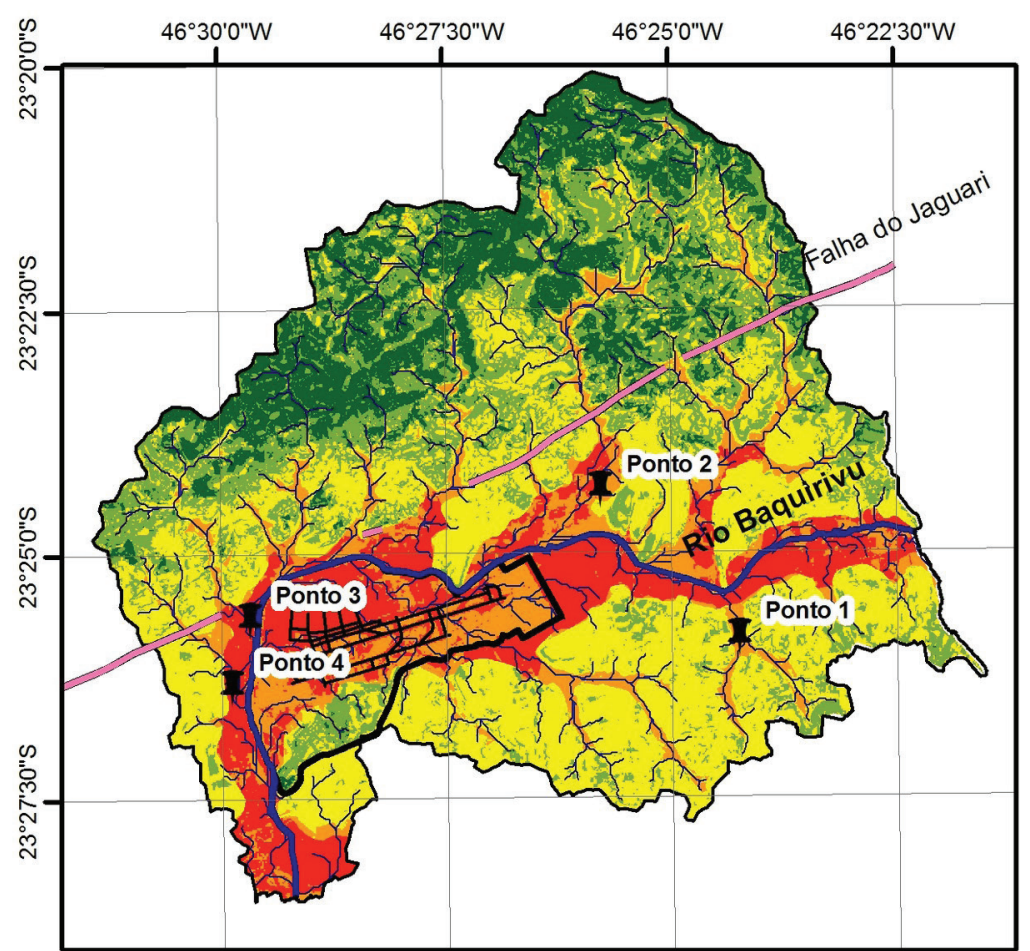

\section{Vulnerabilidade} à inundação

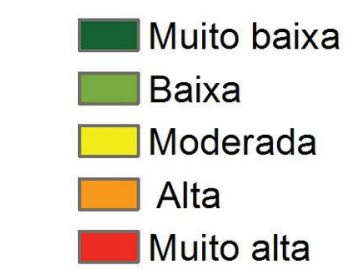

Falha do Rio Jaguari

- Drenagem

- Pistas aeroporto

$\square$ Limite aeroporto

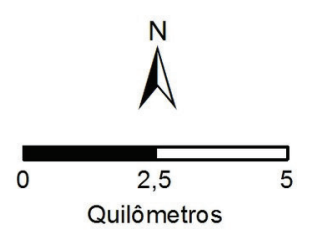

Sistema de coordenadas UTM/SIRGAS 2000 - 23 S

Figura 4. Mapa de áreas vulneráveis a processos de inundação da Bacia Hidrográfica do Rio Baquirivu-Guaçu. Figure 4. Map of areas vulnerable to flooding processes in the Baquirivu-Guaçu River Watershed. 
típica de terreno úmido (Fig. 5A).

O Ponto 2 (46 $\left.25^{\prime} 46.91^{\prime \prime} 0 ; 23^{\circ} 24^{\prime} 21.88^{\prime \prime} \mathrm{S}\right)$ também é classificado como de Alta Vulnerabilidade à Inundação, com terreno bastante plano e presença de casas na beira de um córrego (Fig. 5B).

O Ponto 3 (46²9'41.19"0; $\left.23^{\circ} 25^{\prime} 40.92^{\prime \prime} \mathrm{S}\right)$ está localizado em área classificada como de Muito Alta Vulnerabilidade à Inundação. Já margeando a área do aeroporto, o terreno continua bastante plano, com presença de várias residências dentro do limite que deveria estar destinado à Área de Preservação Permanente de $30 \mathrm{~m}$ para cada lado do córrego (Fig. 5C).

O Ponto 4 (46 $\left.29^{\prime} 53.22^{\prime \prime} 0 ; 23^{\circ} 26^{\prime} 22.16^{\prime \prime} \mathrm{S}\right)$ está localizado ao lado de afluente do Rio Baquirivu, numa área composta por galpões de transportadoras, bastante plana e que sofre seguidamente de processos de inundação, de acordo com relato de pessoas que trabalham na região (Fig. 5D).
A Lei 12.651 de 25 de maio de 2012 (Brasil, 2012) - Novo Código Florestal - no Inciso I do Artigo 4, trata das Áreas de Preservação Permanente de faixas marginais de qualquer curso d'água (rios e córregos) que, em zona urbana, deve ter largura mínima de (desde a borda da calha do leito regular): $30 \mathrm{~m}$ para os cursos de água com menos de $10 \mathrm{~m}$ de largura de lâmina de água (alínea a); 50 m para os cursos de água que tenham largura de lâmina de água entre 10 e 50 (alínea b); 100 m para os cursos de água que tenham largura de lâmina de água entre 50 e 200 (alínea c); 200 m para os cursos de água que tenham largura de lâmina de água entre 200 e 600 (alínea d); e 500 m para os cursos de água que tenham largura de lâmina de água superior 600 m (alínea e).

Nenhum dos córregos que compõem a Bacia Hidrográfıca do rio Baquirivu-Guaçu possui mais de 10 metros de largura. Logo, de acordo com a Alínea a, do Inciso I do Artigo $4^{\circ}$ da Lei

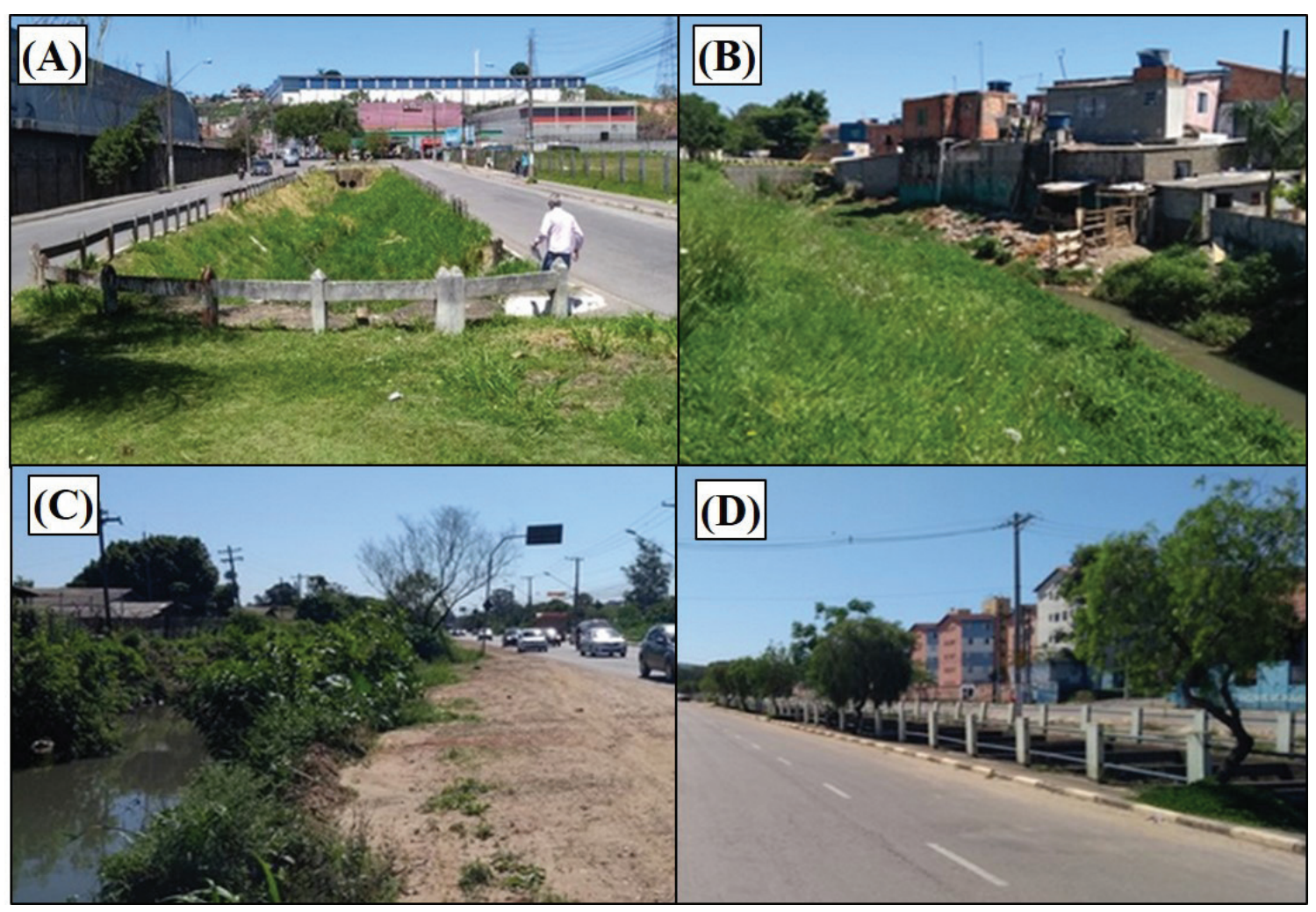

Figura 5. Registro fotográfico de trabalho de campo, realizado em novembro de 2017. As Figuras A, B, C e D representam os pontos visitados em campo: 1, 2, 3 e 4, respectivamente.

Figure 5. Fieldwork photographic record carried out in November 2017. Figures A, B, C and D represent the points visited in the field: 1, 2, 3 and 4, respectively. 
n 12.651/12, a Área de Preservação Ambiental destes corpos de água é uma faixa marginal desde a borda da calha do leito regular, em largura mínima de $30 \mathrm{~m}$. Através de trabalho de campo, verificou-se que essa legislação não é obedecida em nenhum ponto da área de estudo, conforme figuras 5 a 8).

\subsection{Avaliação geoespacial das áreas suscetíveis ao fenômeno de inundação}

A Figura 6 apresenta o mapa de uso e ocupação do solo apenas da região com vulnerabilidade alta e muito alta ao processo de inundação. O número de classes de uso e ocupação do solo não mudou em relação ao mapa da área total (Fig. 2), porém, sim, a representatividade de cada classe. A classe de floresta densa que representa 17,35\% da área total da bacia passa a representar apenas 0,93\% do perímetro delimitado pelas áreas de alta e muito alta vulnerabilidade a inundação.

A classe de vegetação rasteira teve acréscimo da sua participação, pois representa
$27,83 \%$ da área total da bacia, enquanto representa 30,07\% do perímetro de alta e muito alta vulnerabilidade. Esse aumento da representação da classe de vegetação rasteira (gramíneas) deve-se ao espaço entre as pistas do aeroporto que, aliás, tem boa parte da sua estrutura inserida dentro da área de alta e muito alta vulnerabilidade à inundação.

\section{Discussão dos resultados}

Acidente geológico urbano, no contexto expresso por Oliveira (2010), representa a materialização de processos de alteração do meio físico induzidos pelo uso e ocupação da terra, caracterizados pela não obediência a qualquer critério de planejamento (técnico ou legislativo) e que trazem como consequência prejuízos das mais variadas categorias.

As inundações representam, juntamente com os movimentos de massa, processos geológicos de acidentes mais frequentes no Brasil e, por esse motivo, têm recebido alguma atenção por parte das autoridades governamentais.
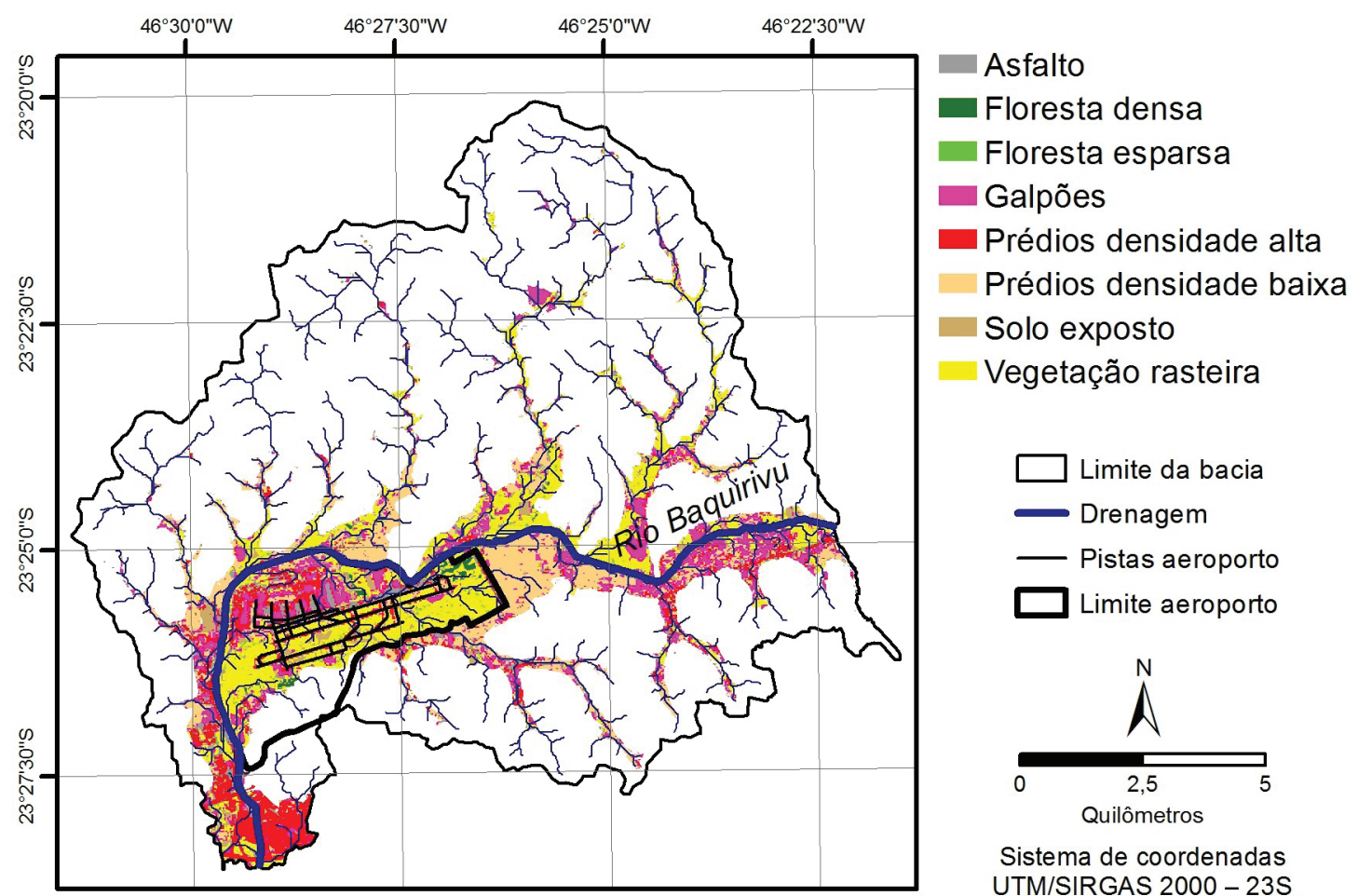

Figura 6. Mapa de uso do solo (recorte de áreas de alta e muito alta vulnerabilidade a processos de inundação da Bacia Hidrográfica do Rio Baquirivu-Guaçu).

Figure 6. Map of land use (cutting of areas of high and very high vulnerability to the flood processes of the BaquirivuGuaçu River Watershed). 
De acordo com o Ministério das Cidades (IPT, 2007), inundação representa o transbordamento das águas de um curso de água, atingindo a planície de inundação. Quando se analisa os condicionantes desse processo, encontra-se uma combinação entre aqueles de origem natural e antrópica (Amaral \& Ribeiro, 2012). Ainda, segundo esses autores, dentre os condicionantes naturais citam-se: formas de relevo; características da rede de drenagem da bacia hidrográfica; intensidade, quantidade, distribuição e frequências das chuvas; características do solo e o teor de umidade; e a presença ou ausência de cobertura vegetal.

As atividades antrópicas podem impactar a paisagem natural de uma bacia hidrográfica de diversas formas (Oliveira, 2010): com ocupação desordenada sobre áreas propensas à inundação constitui um dos principais motivos deflagradores desse processo, pois a urbanização acompanhada da retirada da mata ciliar, remoção da vegetação e impermeabilização do solo constituem agentes que alteram o escoamento natural das águas de superfície. Despejos de resíduos sólidos urbanos; lançamentos de esgotos domésticos e industriais; retificação, aprofundamento, desvios e canalização dos córregos; ocupação indevida das margens de fundo de vale; execução de cortes de aterro na planície de inundação e ausência de saneamento básico são outros fatores apontados por Oliveira (2010) para provocarem inundações.

Tendo por base as análises das características do meio físico (formas de relevo, declividade, tipo de solo, amplitude e padrão dos canais, processos geotécnicos e legislação ambiental), do uso e ocupação do solo e dos históricos das inundações na Bacia do Rio Baquirivu-Guaçu, este trabalho corroborou com as interpretações manifestadas por CPRM (2015), no que se refere à suscetibilidade à inundação no baixo curso do Rio BaquirivuGuaçu. Diante do exposto, conclui-se que as planícies fluviais apresentam espaços adequados à manifestação das inundações naturais, que são incrementadas pelas atividades antrópicas, voltadas à urbanização. Tais fatores conduzem a um quadro ambiental preocupante, pois revela um comportamento com vocação a receber inundações de altas intensidades, frequências e durações, principalmente ao longo do verão, tal como o verificado nos meses de fevereiro e março de 2019, em toda a Região Metropolitana de São Paulo.

\section{Conclusões}

O presente trabalho apresentou resultados satisfatórios na avaliação da suscetibilidade às inundações, atestando a possibilidade de replicação do método para estudos de planejamento em outras bacias hidrográficas. Observando-se os mapas e fotografias registradas nos trabalhos de campo, fica evidente que a falta de infraestrutura urbana favoreceu a transformação dos cursos d'água em verdadeiros depósitos de lixo e sedimentos, comprometendo o adequado funcionamento dos sistemas de drenagem como apresentado no trabalho pela falta de saneamento básico no entorno da Bacia do Rio Baquirivu Guaçu.

As visitas a campo, realizadas na região da Bacia Hidrográfica do Rio BaquirivuGuaçu, foi visto todos esses acontecimentos e apresentadas no trabalho por meio de fotos, que foram complementadas pelos mapas de maneira a confirmá-los.

Foram atribuídos pesos de importância aos planos de informação temática de cada variável escolhida, diretamente relacionados ao conhecimento da área de estudo e da revisão da literatura sobre dinâmica fluvial e inundações. Assim, a geomorfologia (plano de informação temática que recebeu maior peso na modelagem ambiental proposta) foi considerada importante porque reflete as formas criadas pelos processos fluviais sendo que estas formas criadas, hoje, também interferem no funcionamento e na abrangência dos processos fluviais (cheias). As formas de relevo que constituem os fundos de vale (terraços e planície colúvio-aluvionar) se mostraram as mais suscetíveis ao fenômeno das inundações e, infelizmente, são justamente estas áreas da bacia as que recebem ocupação urbana mais densa e, consequentemente, maior impermeabilização do solo.

As inundações em áreas urbanas vêm sendo alvo de intervenções e desenvolvimento 
de instrumentos de ordenamento territorial com vistas a mitigar os danos econômicos e sociais gerados pelas próprias inundações. A intervenção com vistas a redução de inundações urbanas pode ser um sistema de túneis subterrâneos construído com objetivo de dar vazão as águas precipitadas. Além da importante obra de engenharia, medidas não estruturais, ligadas a orientação da população, são constantes com o objetivo de evitar a obstrução dos coletores de água (bueiros) por lixo, além de orientações de condutas em situações de risco.

Para os casos de intervenções estruturais, quanto as de não estruturais, para garantia de um bom nível de eficiência desses sistemas hídricos, é imprescindível realizar a sua manutenção periódica, através de operações de limpeza, desobstrução e desassoreamento, normalmente simples de serem executadas. Com esses procedimentos e operações amenizaria, ou mesmo resolveria algumas vezes, casos de inundações ocorrentes em áreas urbanizadas.

Outras propostas seriam a implantação de reservatórios de retenção. Dessa forma pretendese alterar o regime hidráulico dos cursos d'água da bacia, forçando o armazenamento das águas excedentes em áreas pouco habitadas, de forma a não causar maiores transtornos à população antes de chegar aos pontos mais baixos, como nas planíces condizentes com o que apresenta Giudice (2000), ao citar os planos de recuperação e mitigação das enchentes para essa região.

\section{Referências}

Amaral, R. \& Ribeiro, R.R. 2012. Inundações e Enchentes. In: Tominaga, L.K., Santoro, J. \& Amaral, R.R. (Org.). Desastres Naturais: Conhecer para Prevenir. Instituto Geológico, Secretaria do Meio Ambiente, Governo do Estado de São Paulo, p. 39-52.

Braga, B., Hespanhol, I., Conejo, J.G.L., Barros, M.T.L., Veras, M.S., Porto, M.F.A., Nucci, N.L.R., Juliano, N.M.A. \& Eiger, S. 2005. Introdução à Engenharia Ambiental. São Paulo, Prentice Hall, 305p.

Campos, D.C. \& Oliveira, A.M.S. 2014. O quadro tecnogênico das inundações do rio Baquirivuguaçu, Arujá e Guarulhos, SP. Quaternary and
Environmental Geosciences, 5(2): 93-102.

Congalton, R.A. 1991. Review of Assessing the Accuracy of Classifications of Remotely Sensed Data. Remote Sensing of Environment, 37(1): 35-46.

Congalton, R. \& Green, K. 2009. Assessing the Accuracy of Remotely Sensed Data. Boca Raton, CRC Press. 200p.

CPRM. Serviço Geológico do Brasil. 2015. Carta de suscetibilidade a movimentos gravitacionais de massa e inundações: município de Guarulhos - SP. Rio de Janeiro, IPT. Escala 1:50.000. Disponível em: <http://rigeo.cprm. gov.br/jspui/handle/doc/15178?mode=full >. Acesso em: setembro, 2018.

Diniz, H. N. 1996. Estudo do potencial hidrogeológico da bacia hidrográfica do Rio Baquirivu-Guaçu, municípios de Guarulhos e Arujá, SP. São Paulo, 331p. Tese de Doutorado, Programa de Pós-graduação em Recursos Minerais e Hidrogeologia, Instituto de Geociências, Universidade de São Paulo.

Ferreira, L.S., Prata-Shimomura, A. R., Ferreira, A.T.S. \& Duarte, H.S.D. 2017. Mapping Local Climate Zones for São Paulo Metropolitan Region: a comparison between the local climate zone map and two other local maps. In: PASSIVE LOW ENERGY ARCHITECTURE, 2017. Edinburgh, Escócia, PLEA, p. 255-262.

Giudice, S.L. 2000. Controle de cheias na Bacia Hidrográfica do Rio Baquirivu-Guaçu. Departamento de Águas e Energia Elétrica, São Paulo. <http://www.daee.sp.gov. $\mathrm{br/acervoepesquisa/relatorios/revista/}$ raee0002/reservatorios.htm>. Acesso em: 19 jan. 2018.

Graça, B.A., Saad, A.R., Santos, A.M., Etchebehere, M.L. \& Queiroz, W. 2007. Condicionantes geoambientais no processo histórico da ocupação territorial do Município de Guarulhos, Estado de São Paulo, Brasil. Revista Geociências, 6(1): 163-190.

Guerra, A.J.T. 2003. Processos Erosivos nas Encostas. In: Guerra, A. J. T. \& Cunha, S. B. (Org.) Geomorfologia: uma atualização de bases e conceitos. Rio de Janeiro, Bertrand Brasil. $472 \mathrm{p}$.

IBGE. Instituto Brasileiro de Geografia e Estatística. 2005. Altera a caracterização do 
Sistema Geodésico Brasileiro. Resolução do Presidente. 8 p. 2005. Disponível em: http://www.inde.gov.br/images/inde/ rpr_01_25fev2005.pdf. Acesso em: 19 dez. 2017.

IBGE. Instituto Brasileiro de Geografia e Estatística. 2011. Censo Demográfico, 2010. Características da população e dos domicílios: resultados do universo. Rio de Janeiro: IBGE, 2011. Disponível em: <http://www.ibge.gov. br/home/estatistica/populacao/censo2010/ caracteristicas_da_popula-ção/resultados_ do_universo.pdf>. Acesso em: maio, 2016.

IPT. Instituto de Pesquisas Tecnológicas. 2007. Mapeamento de riscos em encostas e margens de rios. Brasília, Ministério das Cidades, IPT. 176p.

Ielo, E.M. 2015. Estudo de Vulnerabilidade à Inundação no Município de Ourinhos (SP). Rio Claro, 88p. Dissertação de Mestrado, Programa de Pós-graduação em Geociências, Instituto de Geociências e Ciências Exatas, Universidade Estadual Paulista Júlio de Mesquita Filho.

Jensen, J.R. 2005. Introductory Digital Image

Processing: A Remote Sensing Perspective. 3rd Ed., Upper Saddle River, Prenice Hall, Inc. 525p.

Lorena, L.A.N. 2001. Integração de modelos de localização a sistemas de informações geográficas. Gestão \& Produção, 8(2): 180195.

Mesquita, M.V. 2011. Degradação do meio físico em loteamentos nos bairros Invernada, Fortaleza e Água Azul, como estudos de casos da expansão urbana no Município de Guarulhos (SP). Rio Claro, 146p. Tese de Doutorado, Programa de Pós-graduação em Geociências e Meio Ambiente, Instituto de Geociências e Ciências Exatas, Universidade Estadual Paulista.
Myint, S.W., Gober, P., Brazel, A., Grossman-Clarke, S. \& Weng, Q. 2011. Per-pixel vs. object-based classification of urban land cover extraction using high spatial resolution imagery. Remote Sensing of Environment, 115(5): 1145-1161.

Oliveira, L.M. 2010. Acidentes geológicos urbanos. Curitiba - MINEROPAR, Serviço Geológico do Paraná. 78p.

Queiroz, W.D. 2005. Impactos Geoambientais da ocupação urbana na Microbacia Córrego Taquara do Reino-Bairro Novo Recreio, Município de Guarulhos, SP. Guarulhos, 41p. Trabalho de Conclusão de Curso, Especialização em Gestão Ambiental, Universidade Guarulhos.

Ramalho, R.S., Costa, R.G.S. \& Moura, J.R.S. 1999. Problemas ambientais causados por lixões: 0 lixão de Bangu-Zona oeste do município do Rio de Janeiro. In: CONGRESSO BRASILEIRO DE GEOLOGIA DE ENGENHARIA, São Pedro, SP. Anais..., São Pedro, SP. 1: 10p. 1999

Ross, J.L.S. 2012. Landforms and Environmental Planning: potentialities and fragilities. Revista do Departamento de Geografia, Volume Especial 30 Anos. p. 38-51.

Sato, S. \& Andrade, M. 2017. Correlação da evolução temporal do uso da terra e a qualidade das águas superficiais da bacia do Rio Baquirivu-Guaçu, nos municípios de Arujá e Guarulhos (SP). Revista Geociências, 12(1): 26-48.

Stewart, I. D. \& Oke, T. 2012. Local Climate Zone for urban temperature studies. Bulletin of the American Meteorological Society, 93: 18791900.

USGS. United States Geological Survey. 2017. Aquisição de imagens orbitais digitais gratuitas dos satélites Terra/Aqua (MODIS). Disponível em <http://mrtweb.cr.usgs.gov>. Acesso em: 08 dez. 2017. 